\title{
Acer palmatum 'Dissectum' 1
}

\author{
Edward F. Gilman²
}

\section{Introduction}

Japanese maple (Figure 1) has a height and spread of about 20 feet, but there are much smaller selections available. The multiple trunks are muscular-looking, picturesque, grey and show nicely when lit up at night. Japanese maple is grown for its green or red colored leaves, interesting growth habit and fine leaf texture. Fall color ranges from bright yellow through orange and red and is often striking, even on trees grown in total shade. Growth habit varies widely depending on cultivar from globose, branching to the ground to upright, vase-shaped. The globose selections look best when they are allowed to branch to the ground. Be sure to clear all turf away from beneath the branches of these low growing types so the lawn mower will not damage the tree. The more upright selections make nice patio or small shade trees for residential lots, and, with pruning to remove drooping branches, provide adequate clearance for pedestrian traffic to pass close to the tree. More compact cultivars make wonderful accents for any landscape.

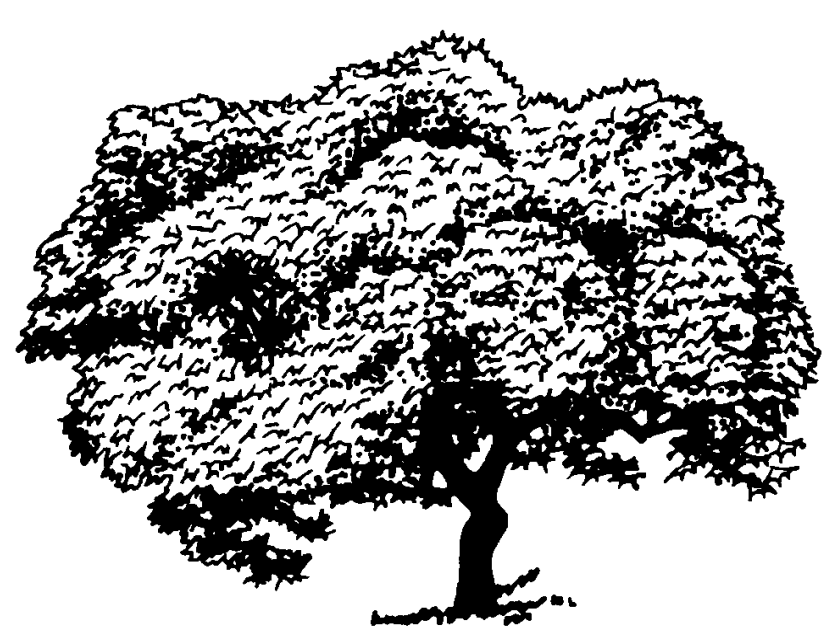

Figure 1. 'Dissectum' Japanese maple.

\section{General Information}

Scientific name: Acer palmatum 'Dissectum'

Pronunciation: AY-sir pal-MAY-tum

Common name(s): 'Dissectum' Japanese maple

1. This document is Fact Sheet FPS-10, one of a series of the Environmental Horticulture Department, Florida Cooperative Extension Service, Institute of Food and and Agricultural Sciences, University of Florida. Publication date: October 1999. Please visit the EDIS web site at http://edis.ifas.ufl.edu.

2. Edward F. Gilman, professor, Environmental Horticulture Department, Cooperative Extension Service, Institute of Food and Agricultural Sciences, University of Florida, Gainesville, 32611.

The Institute of Food and Agricultural Sciences (IFAS) is an Equal Employment Opportunity - Affirmative Action Employer authorized to provide research, educational information and other services only to individuals and institutions that function without regard to race, creed, color, religion, age, disability, sex, sexual orientation, marital status, national origin, political opinions or affiliations. For information on obtaining other extension publications, contact your county Cooperative Extension Service office. Florida Cooperative Extension Service / Institute of Food and Agricultural Sciences / University of Florida / Larry R. Arrington, Interim Dean 
Family: Aceraceae

Plant type: tree

USDA hardiness zones: 5B through 8 (Figure 2)

Planting month for zone 7: year round

Planting month for zone 8: year round

Origin: not native to North America
Foliage

Leaf arrangement: opposite/subopposite

Leaf type: simple

Leaf margin: lobed; parted

Leaf shape: star-shaped

Leaf venation: palmate

Uses: near a deck or patio; specimen; bonsai

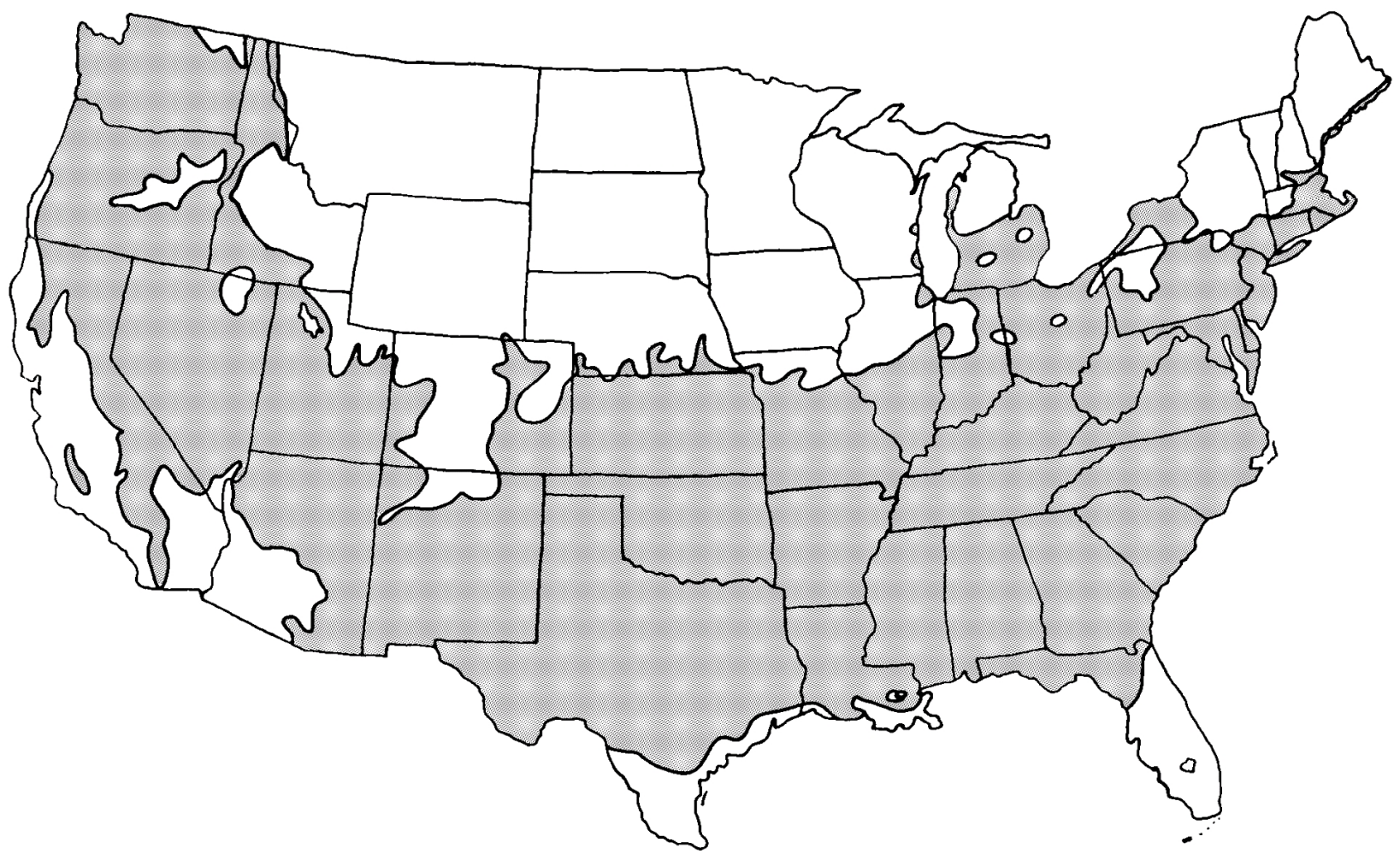

Figure 2. Shaded area represents potential planting range.

\section{Description}

Height: 10 to 15 feet

Spread: 10 to 15 feet

Plant habit: weeping

Plant density: dense

Growth rate: slow

Texture: fine
Leaf type and persistence: deciduous

Leaf blade length: 2 to 4 inches

Leaf color: green

Fall color: orange

Fall characteristic: showy 


\section{Flower}

Flower color: red

Flower characteristic: spring flowering

\section{Fruit}

Fruit shape: elongated

Fruit length: 0.5 to 1 inch

Fruit cover: dry or hard

Fruit color: red

Fruit characteristic: inconspicuous and not showy

\section{Trunk and Branches}

Trunk/bark/branches: showy; no thorns

Current year stem/twig color: reddish

Current year stem/twig thickness: thin

\section{Culture}

Light requirement: plant grows in the shade

Soil tolerances: acidic; well-drained; sand; loam;

Drought tolerance: moderate

Soil salt tolerance: moderate

Plant spacing: not applicable

\section{Other}

Roots: usually not a problem

Winter interest: plant has winter interest because of its unusual form, nice, persistent fruits, showy winter trunk, or winter flowers

Outstanding plant: plant has outstanding ornamental features and could be planted more

Invasive potential: not known to be invasive

Pest resistance: long-term health usually not affected by pests

\section{Use and Management}

This large shrub or small tree tends to leaf out early, so it may be injured by spring frosts. Protect them from drying winds and direct sun by providing exposure to partial or filtered shade and well-drained, acid soil with plenty of organic matter, particularly in the southern part of its range. Leaves often scorch in hot summer weather in USDA hardiness zones 7B and 8 , unless they are in some shade or irrigated during dry weather. More direct sun can be tolerated in the northern part of the range. Be sure drainage is maintained and never allow water to stand around the roots. Japanese maple grows well on clay soils as long as the ground is sloped so water does not accumulate in the soil. It responds well to several inches of mulch placed beneath the canopy.

Variegated types are a bit more difficult to grow and are subject to leaf scorch. There are many cultivars of Japanese maple with a wide variety of leaf shapes, colors, growth habits, and sizes: 'Atropurpureum' - reddish leaves with five lobes; 'Bloodgood' - new foliage bright red, darkening to dark green; 'Burgundy Lace' - reddish foliage and cut leaves; 'Dissectum' - finely dissected leaves in green or red, 10 to 12 feet tall; 'Elegans' - leaves with rose-colored margins when they first unfold; 'Ornatum' - foliage is cut and reddish.

\section{Pests and Diseases}

Aphids infest maples, usually Norway maple, and may be numerous at times. High populations can cause leaf drop. Another sign of heavy aphid infestation is honey-dew that is noticeable on lower leaves and may appear on objects beneath the tree. Aphids are controlled by spraying or they may be left alone. If they are not sprayed, predatory insects will bring the aphid population under control.

Scales are an occasional problem on maples. Perhaps the most common is cottony maple scale. The insect forms a cottony mass on the lower sides of branches. Scales are usually controlled with horticultural oil sprays. Scales may also be controlled with well-timed sprays to kill the crawlers.

If borers become a problem it is an indication the tree is not growing well. Controlling borers involves 
first identifying the borer infesting the tree and then applying insecticides at the proper time.

Scorch occurs during periods of high temperatures accompanied by wind. Trees with diseased or inadequate root systems will also show scorching. When trees do not get enough water they scorch. Scorch symptoms are light brown or tan dead areas between leaf veins. The symptoms are on all parts of the tree or only on the side exposed to sun and wind. Scorching due to dry soil may be overcome by watering. If scorching is due to an inadequate or diseased root system, watering may have no effect.

Nutrient deficiency symptoms are yellow or yellowish green leaves with darker green veins. The most commonly deficient nutrient on maple is manganese. Implanting capsules containing a manganese source in the trunk will alleviate the symptoms. Test soil samples to determine if the soil $\mathrm{pH}$ is too high for best manganese availability. Plants exposed to weed killers may also show similar symptoms.

Tar spot and a variety of leaf spots cause some concern among homeowners but are rarely serious enough for control. 